\title{
Effects of valsartan and amlodipine on cardiorenal protection in Japanese hypertensive patients: the Valsartan Amlodipine Randomized Trial
}

Hiroya Narumi, Hiroyuki Takano, Satoshi Shindo, Miwa Fujita, Hiroshi Mizuma, Yoichi Kuwabara and Issei Komuro, on behalf of the VART Investigators

Hypertension Research (2013) 36, 655; doi:10.1038/hr.2013.54; published online 23 May 2013

Correction to: Hypertension Research (2011) 34, 62-69;

doi:10.1038/hr.2010.186; published online 7 October 2010

The authors of the manuscript would like to correct affiliation of Mr Nobuo Shirahashi, who was mentioned in the acknowledgement section of this article. The correct affiliation of Mr Shirahashi was Novartis Pharma K.K. 


\section{Retraction: Effects of valsartan and amlodipine on cardiorenal protection in Japanese hypertensive patients: the Valsartan Amlodipine Randomized Trial}

Hiroya Narumi, Hiroyuki Takano, Satoshi Shindo, Miwa Fujita, Hiroshi Mizuma, Yoichi Kuwabara and Issei Komuro on behalf of the VART Investigators

Hypertension Research (2017) 40, 103; doi:10.1038/hr.2016.144; published online 3 November 2016

Retraction to: Hypertension Research (2011) 34, 62-69; doi:10.1038/ hr.2010.186

The authors have indicated to the journal that this paper should be retracted as it contains honest errors, which cannot be corrected accurately by the existing data. After careful consideration, Hypertension Research editorial committee formally retracts this paper with agreement of the authors.
This article has published corrigenda in Volume 34, Issue 1, page 152, doi:10.1038/hr.2010.219 and Volume 36, Issue 7, page 655, doi:10.1038/hr.2013.54. These corrigenda are retracted together with the Original Article. 